\title{
The Perspective of Localization in Liaoning Province Tourism Handicraft Design Research
}

\author{
Wang Liuchun \\ College of arts and crafts of Liaoning Economic Vocational Technological Institute \\ Liaoning Shenyang 110122 \\ 646691038@qq.com
}

\begin{abstract}
Key words: arts and crafts; Tourist souvenirs; The tourism market
Abstract. In this study, the development status of Liaoning tourism crafts was analyzed. In addition, aiming at the problems of the relative lack of the new products' development and design in the current market of tourism crafts and the inadequate attention to their design of local tourism sector, the study of tourism crafts design and the inadequate attention to their design of local tourism sector, the study of tourism crafts design in the localization of Liaoning area should be kept up with the times and strengthened production research and development and the construction of marketing environment. It plays an improtant role in the devoloping and promoting the design of the characteristic tourism crafts in Liaoning area.
\end{abstract}

\section{辽宁地区本土化视野下的旅游工艺品设计的研究}

\author{
王柳春 \\ 辽宁经济职业技术学院工艺美术学院 辽宁 沈阳 110122
}

$\underline{646691038 @ q q . c o m}$

关键词:工艺品; 旅游工艺品; 旅游市场

中文摘要.从辽宁旅游工艺品的发展现状入手, 针对目前旅游工艺品市场存在的对新产品在研 发和设计的认识相对欠缺、地方旅游部门对旅游工艺品设计不够重视等问题, 强调辽宁地区 本土化视野下的旅游工艺品设计的研究要与时俱进, 加强生产研发, 加强营销环境的建设, 对 于发展和提升辽宁地区特色旅游工艺品设计的研究具有重要意义和启示作用。

\section{1.辽宁旅游纪念品市场现状及分析}

辽河流域是中华民族灿烂文化的发祥地之一。自秦王朝统一中国, 到大清王朝的建立, 历朝各代在这片土地上留下了众多富有传奇色彩的文物古迹。

近年来, 辽宁地区旅游业发展迅速, 不断完善旅游环境建设的同时, 积极发展旅游工艺 品产业的, 依托辽宁地域下的清文化为主题, 推出更具竞争力的旅游资源。如何在旅游工艺 品市场做出特色是今天我们要思考的问题。

旅游工艺品是旅游业的重要组成部分。随着辽宁旅游消费规模的不断扩大和市场竞争的 升级, 旅游业 “低投入高产出” 的时期已经结束, 旅游相关部门正不断加大对景点的投入, 与之对应的是景点门票价格的逐渐提高, 但却对潜在的旅游工艺品衍生品的广大市场前景重 视不够, 对于旅游工艺品从产品的研发到营销始终落后于南方。在国外很多旅游景点, 游客必 须经过旅游工艺品商店才能走到出口, 或者离开旅游点前必须要经过工艺品商店。商店里的 
旅游工艺品从价值人民币几元的钥匙扣、小挂饰到几百元的画册、几千元的首饰和工艺品应 有尽有。旅游工艺品也分别针对不同人群而设置, 让游客很难空手而归。“中国的旅游商品 缺乏特色和创意” 是不少国内外游客抱怨的焦点。为了改变这种局面, 打开游客的购物钱包, 旅游部门不久前专门把按照特点发展地方旅游纪念品写进了 “十一五” 规划草案。特别是目 前 “低价游” 的盛行, 将旅游者的消费转嫁于旅游工艺品、景点纪念品的购买上, 从侧面也 彰显出旅游工艺品设计和开发的重要性。

旅游作为一种休闲活动自古就受到文人墨客的欢迎, 经济事业的文化性离不开旅游, 或 者说旅游业是特色的经济性文化事业。其中旅游工艺品在旅游业中占有重要的份额。旅游工 艺品是旅游者需求的重要内容之一; 另外旅游工艺品亦能成为宣传旅游目的地的活广告, 有 助于促进当地民族文化的保护和发展, 带动当地的包括旅游业及相关产业的整体经济效益。

以辽宁地区旅游工艺品的发展为例。在辽宁旅游业迅猛发展同时也需要与之相对应的旅 游工艺品、文化衍生品的深度开发。目前蓬勃发展的旅游业市场上简单的、单一的旅游工艺 品已经远远不能满足游客的需求。不足之处表现在产品缺乏特色、没有创新。质量上品质粗 劣, 包装不考究, 不足以给人一种更深入文化的内涵。就旅游工艺品制造行业来看, 总体是 生产企业规模小，技术旧，做工粘，缺乏新产品设计研发的能力。或者工艺品体积大，不方 便携带。例如, 阜新的玛瑙雕刻产品; 岫岩的玉雕产品; 在选材上极具地方特色, 但是由于 不便携带，体积过大，易破损，不易运输等，令很多游客不得不放弃而购买其他类商品。

辽宁地区旅游工艺品发展到目前, 遭遇到越来越多的来自新的形式和新的局面的挑战。 市场上竞争性、挑战性的存在也意味着充满机遇, 只有抓住机遇, 必会有更长远的发展。逐 步打造成实用性、多样性、唯一性、创新性、文化性、礼品性, 旅游工艺品文化衍生性。这 也是辽宁旅游工艺品的发展趋势。

\section{2. 辽宁旅游工艺品制造行业存在的普遍性问题}

以辽宁省为例, 旅游工艺品行业生产企业规模普遍偏小, 一直以来多数产品缺乏创意, 不同地方不同景点的纪念品千篇一律，不能反映地域文化特色。甚至在不同地区景点的旅游 纪念品商店出现相同的纪念品, 这样就使旅游者失去购买的价值。旅游者往往有着相同的体 会, 就是说全国的旅游景点不管走到哪里都能看到相同的、相似的旅游工艺品。而且做工粗 糙、包装简单, 且质量没有保证。作为游工艺品其本身蕴涵着一定的人文意义, 对旅游者来 说既有纪念价值也有收藏价值, 因此纪念品的品质一定要有保证。而我国工艺品市场除价格 昂贵的高档工艺品做工精细以外, 大部分都存在着品质低劣这一普遍现象。其他国家例如东 南亚的泰国、相邻的日本等国旅游工艺品行业近年来发展迅速, 其中一个原因就是它们样样 都比较精致, 粗制滥造的东西极为少见。数千元一块的挂毯和上百美元一个的雕刻工艺品自 不必说, 就连 1 美元一个的冰箱贴和钥匙链也都做工精细, 加上考究的包装, 设计感十足, 游客买来馈赠亲友绝无“拿不出手”之虞。

辽宁省本质上不缺乏旅游资源。而旅游工艺品行业却远远落后于南方城市。不注重人性 化的设计，没有统一的设计体系、体量庞大，不便于携带是最普遍的问题。

旅游工艺品档次分化明显, 高低档工艺品在价格上千差万别, 假货横行, 旅游者、消费 者良莠难分, 特别是商品售卖时吃回扣现象已经成了旅游行业内部公开的潜规则。减小高低 档次商品的差距, 多增加中间层次的商品, 这样可以给予旅游者一定的选择空间, 满足大多 数旅游消费者的需求。

辽宁地区旅游工艺品发展滞后的重要一点是缺乏专业开发人才、研发力量薄弱。目前辽 宁省从事旅游工艺品设计研发人员很少是经过系统旅游专业或者相关专业教育、美术院校旅 游工艺品设计专业人员。往往是旅游专业毕业的人员不懂得工艺品的工艺及设计内涵。而旅 游学校又很少设置旅游工艺品专业及旅游商品销售服务策划类的专业, 这样无形中导致了旅 游工艺品研发人才的缺乏。 
目前，辽宁省内的旅游工艺品生产、加工、研发和销售基本上都是以个人作坊、私企公 司为主。而这些企业多数为加工型企业, 常年对外加工, 大部分商品外贸出口, 依托地方产 业为主的加工型企业例如, 传统的老工艺厂一一羽毛画厂，传统的羽毛画已经不能在市场上 具有一定的竞争优势, 出口创汇的时代, 代表着辽宁省乃至中国的特色工艺品已经处在衰落 下滑的曲线上, 不得不和市场接轨进行订单加工, 这样往往专利权不在企业, 对方随时可以 撤掉订单, 很是被动。岫岩的玛瑙在历史上有过浓重的一笔。发展到现在, 已经是辽宁地方 重要的特色工艺品。在加工工艺上与南方其他城市相比较, 缺乏工艺上的创新, 急需具有设 计意识的专业人才加入, 将岫玉的特点最大的展示出来。贝雕, 是大连的特色旅游工艺品。 单纯从加工和制作销售量来看已经具有一定的规模, 带动了地方产业。大连是我国贝雕的发 源地, 在国内外享有很高的声誉, 其产品远销50多个国家和地区。从传统手工艺品的产品上 来看贝雕等绝对是属于高大上, 往往却得不到年轻人的青睐。时代的发展, 酷爱旅游的年轻 人已经渐渐成为旅游工艺品的消费主力军。而能够打动年轻人的设计却不多见, 相反, 年轻 人却认为贝雕、玉雕、煤精雕和玛瑙雕等等设计上过于中规中矩, 甚至太过传统没有新意。 相反从业的老工艺美术师又面临手艺的传承问题。年轻人不热衷从事纯手工劳作行业, 从业 环境差，工资低，年限长导致传统手工艺无法传承。

\section{3. 辽宁旅游工艺品的设计与创新}

发展辽宁地方特色。在传承传统基础上开发和设计出辽宁特色工艺品衍生品。旅游工艺 品, 作为承载了特定功能和意义的商品, 其设计首先应考虑它的纪念性功能, 要以人为本, 从消费者的需要出发, 充分体现人性化设计理念。同时, 要与地域文化内涵紧密联系在一起, 切实把握好人、设计、文化三者之间紧密相关的联系。如何将地域性文化融入进工艺品设计 中，再依托地方产业将设计融入传统是重要的问题。

首先是功能性。功能作为任何产品满足人的需要的特性, 也应该成为旅游工艺品设计的 核心概念。实用功能反映在产品的技术性能、环境性能和使用性能上。技术性能是产品技术 内涵的表征, 主要取决于产品技术的选择。从目前的旅游工艺品设计与制作来看, 缺乏新的 科技内涵的融入, 更新换代缓慢, 不能适应新时代的人们追求高质量生活的需求, 存在设计 上的滞后性。环境性能反映产品与环境的协调状况, 主要涉及生态和环保方面问题。产品的 使用性能是实用功能的重要方面, 也是艺术设计的着重点之一。对于旅游工艺品来说, 实用 功能显得略微次要一些, 更重要的是它的另两种的功能: 认知和审美。它们是从人的心理需 要上区分出的两种不同性质的精神功能, 更直接的服务于旅游工艺品的纪念性和观赏性功能。

旅游工艺品首先具有纪念性和观赏性, 才能有助于实现产品和人的对话和沟通。旅游工 艺品利用特定材料质地, 发挥传达信息的符号作用, 来表征某种含义。盲目仿效其他类型的 旅游工艺品造型, 会使人产生认知的混乱和误导, 势必会降低其价值和意义。在一定程度上, 旅游工艺品的个性化设计会使它获得更鲜明的表识性, 从众多雷同的产品中突现出来, 更易 于被消费者接受。旅游工艺品的地域识别性设计语言, 不仅可以使工艺品发挥它的认知功能, 使消费者明确了解这个工艺品出自哪个地区? 哪种文化? 哪种工艺? 它意味着什么? 有何典故 等等, 还且可以充分发挥它的审美功能, 给人以亲切温馨的感受和对生活意义的感悟等。譬 如, 有突出地域文化特征的旅游纪念品清文化主题设计, 它能使人很快了解到清文化特点并 唤起旅行者清文化发源地之行的一定情感体验，创造出纪念品特有的情调和氛围来，从而很 好的发挥它的纪念性意义。

旅游工艺品的设计，实质上是一种文化设计。在传统旅游工艺品中占很大比例的手工艺 产品, 往往是与特定的文化传统和习俗联系在一起的, 因此它与人们的日常生活习惯比较接 近, 又暗含人文价值, 容易为人们所接受, 但是手工艺是以个人经验和传统为基础的, 具有 较大的封闭性和保守性。在任何商品生产中, 社会需求决定了要设计和生产什么产品, 社会 的需要具有多样性和发展性, 把握这些需求, 就要把社会的、经济的和文化的进步有机的结 
合起来, 凝结在物质形态的产品之中。旅游工艺品尤其要把握各种文化的独特性与时代性。 文化是在适应环境的条件下产生的，不同的民族和地区会形成不同特色的文化。不同国度有 不同类型的文化，如希腊文化、埃及文化、印度文化和中国文化等。我国又是一个多民族国 家，不同的地域也具有丰富多彩的不同特色的文化，如齐鲁文化、巴蜀文化、楚文化、吴越 文化、两广文化等，每一种文化类型都有特定的构成方式及其稳定的特征。旅游纪念品若想 充分吸引消费者, 在设计时凸显特定地区的独特文化内涵是必不可少的。辽宁抚顺煤精雕刻 工艺品，早在七千年前的沈阳新乐人就用煤精饰品，因为这种非再生资源已日见枯竭，所以 煤精工艺品已被视为即将绝世之宝, 已经发展成为辽宁最具特色的旅游工艺品。煤精雕刻造 型各异、大小不同、风格多样，题材大都缘于生活，反映生活，带有浓厚的地方特色。

任何产品的设计与制作，都是为了适应市场，赢得消费者，旅游纪念品作为旅游业市场 的延伸，并作为潜在的高附加值产业，无疑更要重视市场开发这一环节。

旅游工艺品，应根据工艺品特色类型特征来选择造型、式样并预测到市场的占有程度， 确立设计上的卖点。旅游工艺品设计对于市场开发有重要的作用: 设计具有市场定向作用, 设计师要从模糊的市场需求中把握方向, 为市场开拓提供明确目标。其次, 设计师要不断实 现产品的更新换代, 以便利用科技进步所取得的成果并适应社会生活发展的需要。设计师要 通过提高产品文化内涵和艺术品位, 提升产品价值, 从而创造更高的产品附加值。传统旅游 工艺品, 仍然存在着巨大的市场潜力。关键在于设计师要善于通过工艺品的差别化和细分化, 寻找满足人的需要的新的契合点, 从而主动地开拓市场。还要注意其精神功能, 以及更为人 性化的考虑。比如使旅游纪念品的包装更精良, 携带更便利等; 不仅要重视对人的需求的多 样性和发展变化轨迹的研究, 从而提出新的功能要求, 新的使用方式。还要密切关注当代科 学技术的发展, 因为只有依靠新的科技成果, 才能取得新的工作原理、新的结构方式、新的 材料替代更新的造型能力, 从而适应旅游业市场不断变化的要求和普遍的大众审美取向。此 外, 在产品开发中, 艺术设计的审美创造是实现差别化和品牌特色的重要方面。旅游纪念品 一定要通过审美创造诱导和激发人们的购买欲, 满足人们审美和精神生活的需要, 从而扩大 市场效应。

\section{4. 结束语}

通过确立辽宁地区本土化旅游工艺品设计以清文化为主题和营销环境的不断完善, 可以 促进地方旅游业的更好发展。在发展旅游工艺品设计研发同时, 应当认识到协调发展营销环 境、营销从业人员专业素养的提升。这就需要我们调整营销思路和设计研发深度, 加强辽宁 省清文化为旅游主线发展策略。

\section{致谢}

本文为辽宁经济职业技术学院2017年度院级课题Ljgykt-zd1706《辽宁地区本土化视野下 的旅游工艺品设计的研究》研究成果。

\section{References}

[1] Lin Nanzhi.Tourism Marketing[M]. second edition.Tianjin: Nankai university press.2000.65-66

[2] Feng Wanrong. Tourism souvenir market existing problems and countermeasures[J]. Journal of taiyuan university.2004.(17)35-36

[3] Palmer. The purpose of art design/form and meaning[M]2000. 